\title{
Patrimonio marítimo flotante y legislación marítima
}

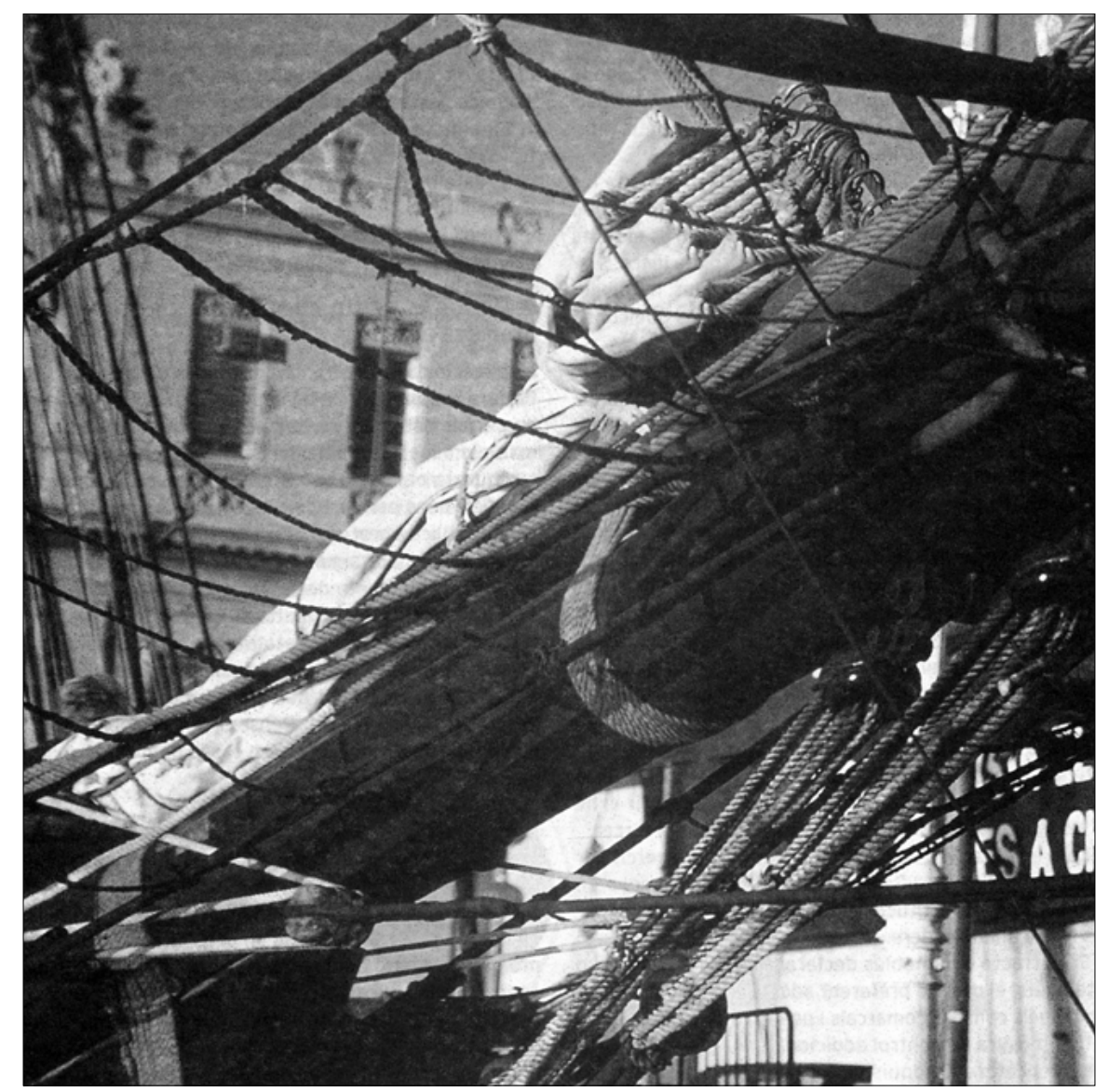

\section{Juan Zamora Terres}

Alex León Arias

Centro de Logística y Servicios Marítimos (CELSEM)

Universidad Politécnica de Cataluña

Este artículo formó parte de las ponencias presentadas en las jornadas "Patrimoni marítim í legislació", celebradas en el Museu Marítim de Barcelona (noviembre de 2000). Con posterioridad, una versión reducida del texto se publicó en el n 9 (p. 76-87) de la revista Drassana de la citada institución. PH agradece al Museo Marítimo y a los autores su desinteresada colaboración para reproducir la contribución y sus ilustraciones.

\section{Resumen}

El compromiso entre mantener el carácter original de cualquier patrimonio histórico y la regulación actual aplicable necesita de una normativa específica que resuelva los numerosos problemas que, indefectiblemente, aparecen. En el caso concreto del patrimonio marítimo flotante (básicamente barcos de época como por ejemplo el Discovery, el Philadelphia, el Fram, etc., todos ellos barcos con una carga histórica importante, o barcos recuperados como es el caso del Santa Eulália), la normativa a aplicar resulta bastante confusa $y$, en líneas generales, inadecuada o simplemente inexistente. A lo largo de este artículo podremos desgranar y analizar las diferentes dificultades y vacíos legales con los que se encontrará un barco histórico en los tres grandes ámbitos de la legislación marítima: el registro marítimo administrativo, la seguridad del barco y los aspectos legales de la dotación. 
0
0
$+\pi$
2
0
0
0
2
0
0
0
0
0
0
0
2
2
0
1
$<$

Este vacío regulador en nuestra normativa puede ser un reflejo del escaso interés que la Administración y los diversos organismos oficiales han mostrado con respecto a una cultura de protección y restauración de nuestro patrimonio marítimo flotante. Pero este mismo argumento es reversible, y quizás sea la falta de motivación cultural-marítima que las empresas privadas y los particulares manifiestan la responsable de la carencia de un desarrollo legislativo particular y específico. Sea como sea, es ahora el momento de comenzar a plantearse una revisión en la regulación aplicable, adaptando las normas existentes, o simplemente creando unas nuevas.

Introducido el barco como monumento flotante, testimonio cultural, técnico y comercial de un tiempo pasado, brinda a aquellas sociedades con amplia cultura marítima (como es la nuestra), la exhibición de un patrimonio específico, muestra de orgullo local, que también ofrece diversas funciones sociales: desde la promoción de la región a nivel internacional, a la actuación del barco como embajador de la región y su cultura marítima, hasta llegar a la simple conservación en la tradición del arte en la navegación. Esto da argumentos suficientes como para justificar un interés general que, hasta hace pocos años, era desconocido, o casi desconocido, entre nosotros. Esta actitud, reciente en España como decimos, contrasta con la experiencia y la tradición existentes en otros países de nuestro entorno cultural. Así no podemos dejar de mencionar el Mystic Seaport Museum en el estado de Connecticut y el South Street Seaport de Nueva York, en los Estados Unidos; o más cercanos: el museo al aire libre de Bremerhaven, el de Hamburgo, los docklands de Londres, o los de Liverpool.

La realidad actual es que podemos encontrar en nuestro país pocos ejemplos de barcos históricos vivos, la mayoría de ellos soportados por asociaciones privadas o museos. Y los pocos que existen sobreviven dentro del confuso mar legislativo a base de exenciones administrativas particulares, o en el caso de los barcos que pertenecen a la Armada, gracias a la letra pequeña de prácticamente toda la normativa marítima aplicable.

Analizada la tendencia social actual de no seguir dando la espalda a la cultura marítima y portuaria (transición de un puerto oscuro y cerrado a una cultura marítima amplia y por descubrir), es de esperar un aumento del patrimonio marítimo flotante en España. $Y$ este despertar ha de encontrarse acompañado por una regulación específica, dentro de un marco común más amplio (por ejemplo, soportado por las normas internacionales de la International Maritime Organization, IMO) que puedan garantizar todos los aspectos legales de este tipo de embarcaciones, muy especialmente con los aspectos referentes a la seguridad del barco y de la navegación.

\section{Palabras clave:}

Legislación marítima / Museos marítimos / Patrimonio marítimo flotante / Patrimonio portuario / Embarcación histórica / Seguridad marítima

\section{PATRIMONIO MARÍTIMO FLOTANTE}

\section{Introducción}

La historia marítima y portuaria de los puertos constituye una parte fundamental en las raíces y en el desarrollo de sus zonas más próximas; el comercio marítimo ha sido un pilar muy importante en la construcción de la mayoría de ciudades costeras. A pesar de esto, el mundo marítimo y portuario resulta un ámbito escondido para los ciudadanos que, con pocas excepciones, al menos durante los últimos 60 años, ignoran el patrimonio marítimo-portuario de su propia ciudad. Si bien es cierto que la situación a comenzado a cambiar desde hace unos años, queda todavía un largo camino por recorrer.

Podemos afirmar que actualmente nuestras ciudades no valoran ni tienen en cuenta su tradición marítima. El contraste con ciudades como Hconurg, Liverpool, o Amsterdam, que cuidan y mantienen este patrimonio con entusiasmo, es evidente.

\section{Muestras sobre Patrimonio Marítimo}

La forma más completa de exposición sobre las actividades portuarias y de la navegación es, sin duda, disponer de un puerto histórico, de una área específica más o menos grande con tres tipos diferentes de espacios: un edificio para las muestras y los servicios a cubierto, un espacio al aire libre en los muelles y un espacio marítimo para atracar uno o varios barcos. Este es el modelo de intervención que, además de ser el más completo y que, por tanto, más posibilidades ofrece desde el punto de vista de realización de muestras y actividades, es también el que más público puede atraer, como lo demuestran las principales experiencias que a continuación brevemente se reseñarán.

\section{Mystic Seapuerto Museum}

En la pequeña población de Mystic en el Estado de Connecticut en los Estados Unidos, aproximadamente a $150 \mathrm{~km}$ al norte de Nueva York, se encuentra uno de los museos marítimos más originales y más visitados del mundo. El museo consiste en la reproducción de una villa portuaria del siglo XIX dedicada fundamentalmente a la pesca y especialmente a la caza de la ballena. La parte terrestre se ha realizado a partir de diferentes edificios (casas, iglesia, talleres, comercio, taberna, almacenes...) que han sido construidos o transportados y restaurados a Mystic desde diferentes lugares del condado y del estado. En los muelles y en los espacios libres se realizan diferentes actividades. En el área marítima están atracados diferentes barcos. El más importante e interesante es el Charles Morgan, único barco ballenero de vela que queda en todo el mundo. También dispone de otros tipos de barcos, especialmente de vela, además de alguno de vapor que sirve para realizar visitas por el puerto. 


\section{South Street Seapuerto en Nueva York}

En una de las zonas portuarias más dinámicas en el pasado de Nueva York, en el famoso South Street, entre el puente de Brooklyn y la terminal de ferrys de Staten Island, se encuentra una amplia área de rehabilitación urbanística conocida como South Street Seapuerto. En esta amplia área conviven diferentes tipos de servicios, equipamientos y actividades urbanas, desde el Mercado del Pescado hasta centros comerciales como el Fulton Market o el Pier 17. Uno de los equipamientos culturales que inició la transformación de esta zona y que en la actualidad atrae a más público es el South Street Seapuerto Museum, creado el año 1968 por una asociación privada de voluntarios. Este museo tiene unas características especiales ya que no dispone de un gran local en tierra donde realizar todas sus actividades sino que cuenta con cuatro edificios diferentes de dimensiones medias y relativamente separados donde se pueden realizar diversas actividades y exhibiciones. Además, cuenta con un gran espacio en los muelles donde están atracados diferentes barcos, algunos de los cuales navegan por el Hudson y el East River. El más famoso de los barcos atracados es el Pekin ( 1911 ), que realizó durante años la ruta del Cabo de Hornos y del que se dispone de una de las pocas películas documentales atravesando este lugar con un temporal. Además, el South Street Seapuerto Museum cuenta con:

- El barco Conrose (1908).

- El velero "full rigged" Wavertree ( 1885 ).

- El "steam ferry" General William H. Hart (1925).

- El remolcador W. O. Decker (1930).

- Dos goletas: Pionner ( 1885$)$, y Letie G. Howard (1899).

\section{El museo al aire libre de Bremerhaven}

Bremerhaven como puerto y como ciudad fue construida a partir del 1827 . El proyecto respondía a la necesidad de la ciudad de Bremen de disponer de un puerto de mayor calado y más próximo a la desembocadura Weser. Por este motivo la moderna ciudad de Bremerhaven da una gran importancia a su puerto creando en 197/ uno de los museos marítimos más importantes de Alemania, el Deutsches Schiffahrts Museum. Este dispone de un gran y moderno edificio dedicado a las actividades tradicionales del museo (donde se conserva la famosa coca hanseática de Bremen, del siglo XV), y unos muy amplios e interesantes espacios en los muelles que han llamado Museo al aire libre.

El Museo al aire libre se extiende por un muelle de gran superficie convertido en parque y paseo, disponiendo de una extensa lámina de agua donde hay atracados ocho barcos de diferentes épocas. Los más destacados son: el barco-faro Elba III (no confundirlo con el Elba 3 expuesto a Hconurg), el remolcador Seefalke, el ballenero Rau IX, el Grouland de las expediciones árticas alemanas y el velero Sente Deern.

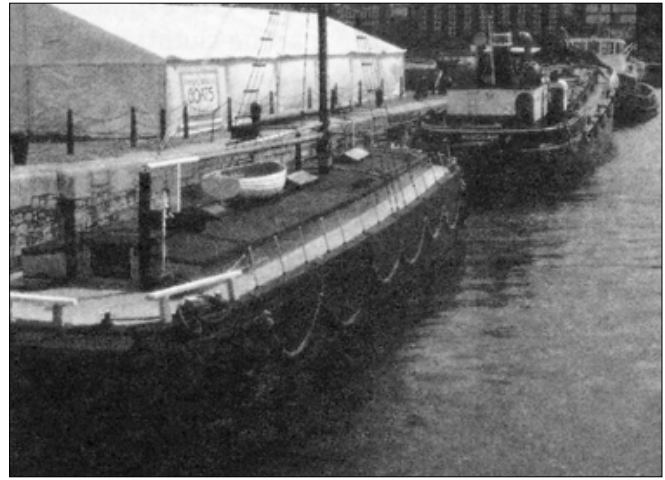

La tradición marítima y portuaria del Reino Unido, sin duda una de las más extensas y ricas del mundo, está recogida en numerosas instituciones, centros culturales y asociaciones repartidas por todo el territorio del país. El número de estos es muy elevado en la capital, Londres, abarcando desde instituciones que dependen del Gobierno Central (como el prestigioso National Maritime Museum) a Asociaciones privadas sin ánimo de lucro que se dedican a comprar y conservar barcos históricos (como Friends of the Maritime Trust).

A lo largo de los viejos docklands (muelles) rehabilitados del puerto de Londres, desde Saint Katharine's Dock hasta la desembocadura del Támesis, se encuentran diferentes experiencias de conservación y exhibición del patrimonio marítimo y portuario. Numerosos edificios rehabilitados en todos los viejos docks; barcos históricos atracados en los muelles como el Discovery, el Belfast o un dique seco como el Cutty Sark, barcos de trabajo conservados por el Maritime Trust; centros como el Museum in Docklands Project dedicado a recoger el patrimonio del puerto y dependiente del Museo de Londres; el National Maritime Museum a Greenwicht, etc.

\section{Los docklands de Liverpool}

Entre las múltiples rehabilitaciones de espacios portuarios realizados en Gran Bretaña destaca, por su extensión y por el rigor con que se han conservado y restaurado los principales edificios e instalaciones técnicas, la de Liverpool. Se inició el año 198 I con la creación de la Merseyside Development Corporation que tenía el objetivo de rehabilitar el área del South Docks pero se amplió considerablemente el 1988 hasta 960 hectáreas, en vista del éxito que se havia obtenido con la restauración del Albert Docks.

\section{El ejemplo de Hconurg}

La ciudad hanseática de Hconurg constituye un ejemplo y un espejo de conservación de las tradiciones y el patrimonio marítimo y portuario.

Destacamos dos elementos:

I. El Museo del Barco. Situado al aire libre, cerca del famoso Mercado del Pescado (Fisch-markt), el Museo 
está formado por una colección de barcos antiguos y tradicionales del Mar del Norte, no muy grandes, entre 15 y 25 metros de eslora, atracados de punta a un muelle de madera perpendicular a la orilla del río Elba. En este muelle se exponen al público los planos, nombre y las características de los barcos que componen este Museo flotante.

En el mismo espacio, se exhiben otros barcos antiguos, de hierro y más grandes: un remolcador de principios de siglo llamado Otto Lauffer; otro remolcador, el Stettin, más grande y un poco más moderno; una draga del primer tercio del siglo $X X$; y un barco de comercio del río Elba de inicios de siglo. El remolcador Sttetin, gestionado por el Museo del Trabajo de Hconurg, y el barco de comercio disponen de servicios de cafetería abiertos al público.

2. La riqueza de barcos antiguos conservados y expuestos en el centro marítimo de Hconurg (Landungsbrücken). Encontramos: un clipper construido en Bremen a finales del siglo XIX, que durante muchos años fue el barco escuela de la Marina de Guerra de Portugal, el Rikmer Rikmers ; un barco-faro, el Elba3, algo posterior al clipper, que va estuvo en servicio hasta la década de los setenta; un buque mercante relativamente moderno, el Cabo San Diego, construido a comienzos de la década de los cincuenta; $y$ diversos barcos fluviales antiguos mantenidos en activo para hacer excursiones por el Elba.

\section{Douarnenez}

Los orígenes de esta iniciativa se remontan al año 1981 cuando un grupo de aficionados por el patrimonio marítimo fundaron la revista Le Chasse-Marée. Entonces la tirada de la revista era de 7.000 ejemplares, actualmente supera los 40.000 .

Hoy en día Le Puerto-Mussée está sustentado por la colaboración entre Le Chasse-Marée, L'Association Treizour, la Fédération Régionale pour la Culture maritime (FRCM) y el Ayuntamiento de Douarnenez. Problemas financieros mantienen el proyecto provisionalmente inacabado.
De esta experiencia nos parece muy remarcable el importante papel que juegan los diferentes festivales marítimos que se celebran con carácter bianual. La concentración de veleros del año 1992, celebrada conjuntamente con la ciudad de Brest, tuvo carácter mundial y supuso la conversión de Douarnenez en un punto de referencia de la conservación, estudio y difusión del patrimonio marítimo europeo.

Se ha de destacar, como otra experiencia interesante de la Bretaña, la conservación en Concarneau, uno de los centros pesqueros más importantes de Francia, del barco Hemerique. Se trata de una embarcación de pesca de los años cincuenta, perfectamente conservada con todo el equipamiento y que se ha convertido en un exitoso polo de interés cultural. Existe un paralelismo evidente entre el Cabo San Diego, en Hconurg, y el Hemerique. En los dos casos han realizado la misma apuesta: lo que hoy es viejo, mañana será historia.

Del análisis de las principales experiencias internacionales comentadas se pueden obtener un conjunto importante de elementos de reflexión.

\section{Elementos de reflexión}

En primer lugar, el hecho de que las exposiciones están profundamente arraigadas en la historia local, constituyendo esto un sello distintivo de cada experiencia.

En segundo lugar, los proyectos de exposición han representado una alta rentabilidad económica, social y cultural para los Museos, los puertos y para las ciudades.

En tercer lugar, detrás de cada experiencia hay un importante trabajo de investigación histórica, elaboración y divulgación; estos trabajos han supuesto generalmente la participación de las universidades e investigadores particulares.

En cuarto lugar, existe una intensa relación públicaprivada con la implicación de numerosas personas y asociaciones que han aportado elementos, ideas y trabajo pera el desarrollo y mantenimiento de los diferentes proyectos. Los ejemplos del Cabo San Diego (Hconurg), y del Hemerique, con un voluntariado que a menudo a tenido alguna relación con la vida activa del barco, es muy elocuente. En otro sentido, como es lógico, encontramos en todos los casos una participación financiera e inversiones privadas que garantizan una gestión económica adecuada.

Por último, muchas experiencias sólo se explican teniendo presente una fuerte intervención de las ciudades, y por tanto una intensa y beneficiosa relación puerto-ciudad. En algunas ciudades, determinados elementos del patrimonio marítimo y portuario se exhiben en plazas y calles, con la doble finalidad de hacer conocer este patrimonio (anclas, boyas, maquinaria diversa, etc.), y servir de elementos decorativos urbanos: los elementos o piezas que hoy se consideran simplemente viejos, mañana serán elementos históricos de valor 


\section{EI Barco como monumento flotante}

Como ya hemos podido ver, muchos puertos del mundo tienen barcos históricos atracados en sus muelles interiores y exposiciones, más o menos grandes, que explican su propia historia. La mayor parte de las ciudades portuarias históricas de América, de Europa y de Oceanía y algunas de las más importantes de Asia tienen instalaciones específicas (centros, Museos, exposiciones...) dedicadas a los objetivos de conservar algunos barcos históricos y explicar la evolución del propio puerto, a través de documentos, representaciones gráficas y algunos elementos materiales. No obstante esto, a título de ejemplo, podemos mencionar unos pocos barcos que creemos fundamentales, prácticamente todos por que participaron en algún hecho histórico que los convierte en elementos simbólicos y muy representativos del propio país. Sin intentar elaborar una lista completa se poden citar los siguientes:

- El Vasa (I627) en Estocolmo, recuperado el 196I, exhibido en un Museo específico;

- El Mary Rose (1510), el Victory (1765) y el Warrior (1860), tres barcos muy diferentes pero perfectamente conservados en Portsmouth;

- El Discovery (190I) de las exploraciones a la Antártida;

- El acorazado Belfast (1938) y el más famoso clipper, el Cutty Sark ( 1869 ) conservados y exhibidos en diferentes muelles del Támesis londinense;

- La fragata norte-americana Constitution ( 1797), hoy Museo de la US Navy en el puerto de Boston;

- El Fram ( 1892 ), utilizado por Amundsen en la conquista del Polo Sur se exhibe en el puerto de Oslo;

- El acorazado Aurora (1900), de la revolución de 1917 en el puerto de Sant Petersburg;

- El Philadelphia (1776), conservado por la Smithsonian Institution en el puerto de Washington;

- La corbeta Uruguay ( 890 ), que participó en el rescate de la expedición antártica Nordensk-jold el 1903 y que se conserva en Puerto Madero (Buenos Aires).

Con todo lo que hasta ahora hemos explicado, no hemos querido hacer otra cosa que remarcar la importancia que el barco adquiere, dentro del Patrimonio Marítimo. Resumidamente podemos extraer los hitos más importantes que el barco, entendido como monumento flotante, proporciona.

- Conservación del patrimonio marítimo.

- Testimonio cultural, técnico y comercial.

- Patrimonio local, orgullo local.

- Herramienta de transmisión y enseñanza para generaciones futuras.

- Mantener la tradición de la navegación.

- Centro de atracción, entretenimiento y diversión.

- Actuar como embajador de la región.

- Promoción internacional.

Como veremos en el siguiente punto de esta ponencia, en el momento que el barco histórico incluye, dentro de su plan de usos, la función de la navegación (función principal por la cual el barco ha sido diseñado), todo el peso de la actual legislación marítima, recae sobre él.

\section{LEGISLACIÓN MARÍTIMA}

Siguiendo con el discurso del punto anterior, nos encontramos un barco con características históricas, que ha de cumplir una legislación "moderna" para él, lógicamente desfasada para su tiempo de construcción, y que en algunos casos puede desvirtuar los elementos básicos característicos de este tipo de embarcación.

Según la actual legislación, cualquier barco histórico es un "barco civil" según la definición genérica que hace la Ley de Puertos del Estado y de la Marina Mercante (LPEMM), artículo 8.2, que únicamente excluye de su ámbito de aplicación a las embarcaciones de l'Armada:

Se entiende por barco civil cualquier embarcación, plataforma o artefacto flotante, con o sin desplazamiento, apto para la navegación y no afecto al servicio de la defensa nacional.

No es sin embargo, un barco mercante. La LPEMM distingue, entre barcos civiles, y barcos mercantes (artículo 8.3):

Se entiende por barco mercante, todo aquel barco civil utilizado para la navegación con un propósito mercantil, excluidos los dedicados a la pesca.

Un vez aclarado el punto anterior (todos los barcos, a excepción de los dedicados a la defensa, forman parte de la flota civil), y en relación a los artículos 74 y 86 de la LPEMM, queda fuera de dudas la competencia del Ministerio de Fomento en todo aquello que afecta a su seguridad y a su control administrativo.

Todos los barcos civiles españoles, independientemente del tipo de carga que transporten, de su actividad y de la zona de navegación que utilicen, están sujetos a un complejo proceso técnico y administrativo de control, de competencia exclusiva del Estado.

Corresponde a la Dirección General de la Marina Mercante (a partir de ahora DGMM), órgano directivo dependiente del Ministerio de Fomento, y a las Capitanías Marítimas como órganos periféricos de la DGMM, ejercer todas las funciones de control previstas en la normativa vigente. El artículo 88 de la LPEMM ("Capitanía Marítima. Funciones") otorga al Capitán Marítimo la función del despacho de barcos, "sin perjuicio de las perceptivas autorizaciones previas que pudieran corresponder a otras autoridades"; la facultad de supervisión de la inspección técnica de los barcos civiles españoles "y de aquellos que se encuentren en construcción"; y en general "todas aquellas funciones relativas a la navegación, seguridad marítima (...) en aguas situadas en zonas en las cuales el Estado español ejerza soberanía, derechos soberanos o jurisdicción". El artículo 1 I 2 de la misma Ley concede a las Capitanías Marítimas el derecho a "visitar, inspeccionar, condicionar el fondeo", etc. a cualquier embarcación que, en aguas españolas, pueda poner en riesgo la seguridad de la navegación o el medioambiente marino. 


\section{Registros Administrativos}

La naturaleza jurídica de un barco' requiere un doble registro: uno de carácter público-administrativo, que se llama Registro de Matrícula de Barcos, o Registre Marítimo (RMV) del cual es competente la Dirección General de la Marina Mercante (Ministerio de Fomento) y sus órganos periféricos, las Capitanías Marítimas². y otro que recogerá las incidencias jurídico-privadas del barco y que se efectúa en el Registre Mercantil (RM) 3 .

La inscripción en el Registro Mercantil del barco histórico puede ser objeto de controversia. El artículo I 46 del Reglamento del Registro Mercantil de 1956 establece que la obligación registral comprende no sólo a las embarcaciones destinadas a la navegación de cabotaje o altura, sino también los diques flotantes, pontones, dragas, gánguiles y cualquier otro aparato flotante destinado o que pueda destinarse a servicios de la industria o comercio marítimo o fluvial. De esta amplísima definición deberíamos deducir la obligación del barco histórico de estar inscrito en el RM. Pero, de su naturaleza de barco público, no destinado ni a la industria ni al comercio, podríamos concluir lo contrario.

El registre marítimo, matriculación y abanderamiento de un barco, es un trámite administrativo obligatorio que tiene por finalidad otorgar el derecho de enarbolar la bandera del país, permitiendo a la Administración de ese país ejercer sus facultades y deberes con respecto al barco. Un barco sin bandera sería considerado un barco pirata. Por el artículo 5 del Convenio Internacional sobre Alta Mar, realizado en Ginebra el 29 de abril de 19584, "Cada Estado establecerá los requisitos necesarios para poder conceder su nacionalidad a los barcos, así como para que puedan ser inscritos en su territorio en un registro y tengan el derecho a enarbolar su bandera (...) el Estado ha de ejercitar efectivamente su jurisdicción y su autoridad sobre los barcos que enarbolen su pabellón en los aspectos administrativo, técnico y social". En España esta obligación se superpone a la de registrar el barco en el Registro Mercantil de Barcos, de forma que existe un doble registro paralelo, o como dicen los profesores Ruiz Soroa y Gabaldon García, una completa duplicidad registral de barcos 5 .

El Registro Marítimo viene recogido en los artículos 75 y 76 de la LPEMM:

Artículo 75. Registro de barcos y Empresas navieras'.

I. El Registro de barcos y Empresas navieras es un registro público de carácter administrativo que tiene por objeto la inscripción de:

- Los barcos abanderados en España.

- Las Empresas navieras españolas.

2. A efectos de su identificación, en la inscripción de los barcos se hará constar todas sus circunstancias esenciales y sus modificaciones, así como los actos y contratos por los que se adquiera o transmita su propiedad, los de constitución de hipotecas o imposición de derechos reales y cualquier otro extremo que se determine legal o reglamentariamente.

3. En la inscripción de las Empresas navieras se hará constar el acto constitutivo y sus modificaciones, el nombramiento y cese de sus administradores, los barcos de su propiedad o que exploten, y cualquier otra circunstancia que se determine legal o reglamentariamente.

4. La inscripción en el Registro de barcos y Empresas navieras no exime del cumplimiento de los deberes de inscripción en otros Registros públicos que puedan existir.

(...)

Artículo 76. Abanderamiento de barcos.

I. Los barcos debidamente registrados y abanderados en España tendrán a todos los efectos la nacionalidad española.

2. Estarán facultados para obtener el registro y el abanderamiento de barcos civiles las personas físicas residentes y las personas jurídicas domiciliadas en España o países de la Comunidad Económica Europea siempre que, en este último caso, designen un representante en España.

(..)

4. Las condiciones de todo tipo que deben ser cumplimentadas con carácter previo a la concesión del abanderamiento en España se establecerán reglamentariamente.

Esta remisión reglamentaria que hace la LPEMM hace referencia al Decreto 1027/89 sobre Registro, Abanderamiento y Registre Marítimo (a partir de ahora DARM $)^{7}$, que en su artículo primero establece:

La presente disposición se aplica a todos los barcos, embarcaciones y artefactos navales, cualquiera que sea su procedencia, tonelaje o actividad.

Los Registros Marítimos, públicos y de carácter administrativo, se organizan mediante libros foliados llamados Listas que se llevan en cada Distrito Marítimo, donde "se registrarán los barcos, embarcaciones y artefactos flotantes según su procedencia y actividad, según se expresa" (artículo 3 del DARM):

a) En la Lista Primera, se registrarán las plataformas de extracción de productos del subsuelo marino, los remolcadores de altura, los barcos de apoyo y los dedicados al suministro a dichas plataformas que no estén registrados en otra lista.

b) En la Lista Segunda, se registrarán los barcos de construcción nacional o importados con arreglo a la legislación vigente que se dediquen al transporte marítimo de pasajeros, de mercancías o de ambos.

c) En la Lista Tercera, se registrarán los barcos de construcción nacional o importados con arreglo a la legislación vigente destinados, a la captura y extracción con fines comerciales de pescado y de otros recursos marinos vivos.

d) En la Lista Cuarta, se registrarán las embarcaciones auxiliares de pesca, las auxiliares de explotaciones de acuicultura y los artefactos dedicados al cultivo o estabulación de especies marinas.

e) En la Lista Quinta, se registrarán los remolcadores, embarcaciones y artefactos navales dedicados a los servicios de puertos, radas y bahías.

f) En la Lista Sexta, se registrarán las embarcaciones 
deportivas de recreo que se exploten con fines lucrativos.

g) En la Lista Séptima, se registrarán las embarcaciones de construcción nacional o debidamente importadas, de cualquier tipo y cuyo uso exclusivo sea la práctica del deporte sin propósito lucrativo o la pesca no profesional.

h) En la Lista Octava, se registrarán los barcos y embarcaciones pertenecientes a organismos de carácter público tanto de ámbito nacional como autonómico o local.

i) En la Lista Novena o de "Registro Provisional", se anotarán con este carácter los barcos, embarcaciones o artefactos navales en construcción desde el momento que esta se autoriza, exceptuándose las embarcaciones deportivas construidas en serie, con la debida autorización.

\section{Aspectos legales de la dotación}

La dotación de una embarcación está constituida por el conjunto de personas ocupadas a bordo que hacen posible la actividad segura y eficaz del barco. La dotación la formen: el capitán; los oficiales; y la tripulación. En general, la composición de la dotación de un barco (nombre, titulaciones, categorías) sigue un triple criterio.

\section{Exigencias de la seguridad marítima}

En primer lugar, las exigencias de la Administración Marítima que, por razones de seguridad y prevención de la contaminación marina, exigen para cada barco una dotación mínima de seguridad y unas titulaciones y certificados que garanticen un nivel determinado de conocimientos en función del tonelaje y construcción del barco, su potencia y equipamiento, y su actividad.

La dotación mínima de seguridad viene exigida por el Convenio Internacional SEVIMAR, Regla I 3 del Capítulo $V$ (único capítulo aplicable a todo los barcos, de cualquier tonelaje y en cualquier viaje, con las únicas excepciones de los barcos de guerra y aquellos que navegan por los Grandes Lagos de Norte-América):

a) Los Gobiernos contratantes se obligan, en relación con los barcos de sus respectivos países a mantener $\mathrm{O}$, si es necesario, adoptar medidas que garanticen que desde el punto de vista de seguridad de la vida humana en el mar dichos barcos llevarán dotación suficiente y competente.

El apartado b) de la Regla 13 obliga "a todo barco al que se apliquen las disposiciones del Capítulo y del presente Convenio un documento adecuado"'(es decir, que no resulta aplicable, como el párrafo anterior a todos los barcos), expedido por la Administración como prueba de que cumple el mandato contenido en el apartado a).

La composición de esta dotación de seguridad ha de seguir los criterios contenidos en la Resolución A.48I (XII), aprobada el 19 de noviembre de 198 I

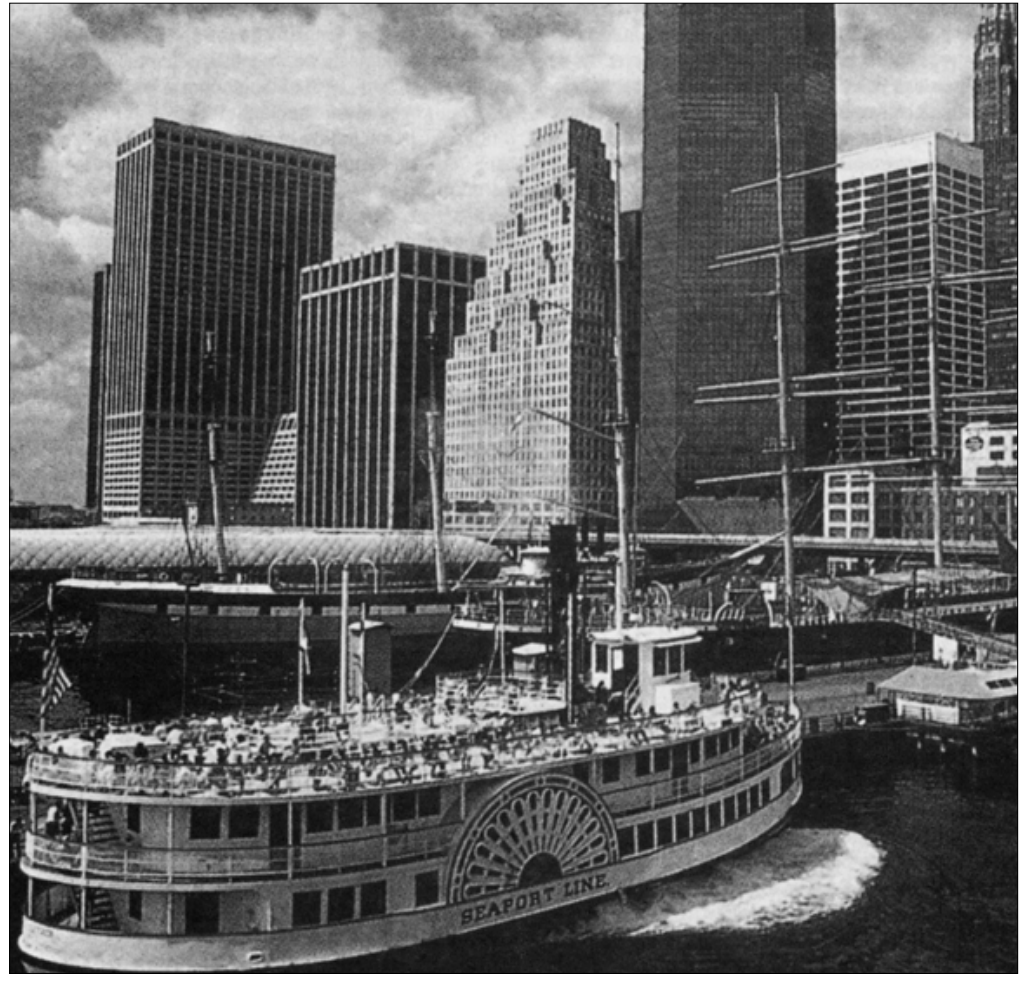

por la Asamblea General de la Organización Marítima Internacional (OMI), llamada Principios relativos a la dotación de seguridad. Estos principios están basados en el respeto a la normativa laboral marítima surgida de la Organización Internacional del Trabajo (OIT), y sobre todo de la aplicación del Convenio Internacional sobre Normas de Formación, Titulación y Guardias (STCW, siglas inglesas por las cuales se conoce) $)^{8}$.

\section{En concreto:}

Las presentes Directrices deben seguirse al aplicar los principios fundamentales relativos a la dotación de seguridad con el fin de garantizar la utilización sin riesgos de los barcos a que hace referencia el Artículo III del Convenio de Formación, 1978. Tal aplicación podrá variar en armonía con factores tales como los siguientes:

I. Descripción del viaje, incluidos el tráfico o los tráficos a que se dedique el barco, la duración y la índole del viaje y las aguas en que se vaya a navegar; 2. Número, potencia (en kW) y tipo de máquinas propulsoras principales y de máquinas auxiliares; 3. Dimensiones del barco;

4. Construcción y equipo técnico del barco.

(...)

Al aplicar las presentes Directrices la Administración tendrá presente que debe contarse con un número suficiente de miembros competentes del personal para hacer frente a las situaciones y condiciones de actividad máxima, habida cuenta del número de horas de servicio a bordo y de los períodos de descanso que procede asignar a un hombre de mar.

Toda Administración podrá mantener o adoptar disposiciones que difieran de las recomendadas aquí, 
especialmente adaptadas a adelantos técnicos y a tipos especiales de barcos y de tráficos. No obstante, la Administración habrá de tener la certeza en todo momento de que las disposiciones detalladas que se tomen en cuanto a dotación dan un grado de seguridad por lo menos equivalente al que establecen las presentes Directrices.

Tenemos que hacer constar aquí que la normativa española, tanto la laboral como de titulaciones marítimas, supera con creces los mínimos internacionales recogidos en los Convenios internacionales sobre la materia, tanto de la OMI como de la OIT.

Anterior a esta normativa de carácter internacional, existe una Orden de 14.07.1964 sobre Cuadro Indicador de tripulaciones mínimas para barcos mercantes y de pesca9, que no ha estado derogada si bien su aplicación práctica es hoy en día casi nula.

\section{Normativa laboral}

La dotación del barco ha de cumplir con la normativa sobre condiciones de trabajo enmarcada dentro del Derecho Laboral. A la gente de mar enrolada en barcos con bandera española se les aplica la misma normativa laboral que al resto de los trabajadores, básicamente el Estatuto de los Trabajadores (jornada, descanso, vacaciones, seguridad e higiene en el trabajo, etc) ${ }^{10}$. Existen, de todas formas, una norma específica sobre jornadas especiales de trabajo y tiempos de descanso para algunos oficios, entre ellos el trabajo del mar, que deja fuera de jornada al capitán del barco, al jefe de máquinas y a oficiales no sujetos a guardias". Para las categorías sujetas a esta norma se realiza la distinción entre jornada efectiva de trabajo y tiempo de espera a bordo, distinción fundamental para la compatibilidad de la jornada en el cómputo semanal y el cálculo de las horas extras, sujetas a una estricta limitación.

La dotación de un barco ha de observar esta normativa laboral, adaptando su número y categorías a su cumplimiento.

\section{Actividad de la embarcación}

No hay bastante con observar con atención los requisitos mínimos impuestos por la normativa. Con independencia de las obligaciones que hace falta cumplir para el Armador, tanto de tipo marítimo como laboral, la composición de la dotación de un barco ha de garantizar la eficacia y la seguridad de las actividades que el barco tenga encargadas. Podríamos decir que este es el criterio fundamental. ¿Cuántas personas son necesarias para llevar a cabo las actividades que el Armador encargue a la embarcación?, ¿Con qué conocimientos?, ¿Con qué perfil? Responder a estas preguntas, tomando como límite bajo los mínimos normativos, constituye una tarea específica del naviero/armador en el momento de seleccionar y contratar a los miembros de la dotación.

\section{Requisitos de Seguridad}

Posiblemente sea este el tema legislativo más delicado y conflictivo en relación a cualquier barco histórico. Delicado, porque hay (y habrá), una tensión permanente entre las exigencias actuales de seguridad, del barco y de la navegación, y el propósito de conservar y mantener con la máxima fidelidad el barco original. Encontrar un equilibrio satisfactorio entre ambas líneas no será siempre una cuestión sencilla.

Y también conflictivo, como veremos más adelante, entre una normativa que no contempla, en general, la posibilidad de adaptarse a las necesidades de una embarcación tradicional.

\section{Seguridad}

El texto básico que regula las condiciones de seguridad de un barco es el Convenio Internacional para la Seguridad de la Vida Humana en la Mar (de ahora en adelante SEVIMAR, si bien nos encontramos con su acrónimo en inglés SOLAS, Safety of Life At Sea), del cual España forma parte.

A nivel interno, la norma más importante es el Reglamento de Reconocimiento de Barcos y Embarcaciones Mercantes, Decreto 3384/1971, de 28 de octubre (de aquí en adelante RRV) ${ }^{12}$.

\section{El Convenio Internacional SEVIMAR}

El Convenio Internacional para la Seguridad de la Vida Humana en la Mar nació el 1914 como consecuencia directa de la catástrofe del Titanic y desde entonces ha tenido diversas versiones, la última de las cuales, vigente en la actualidad proviene de 1974, con importantes modificaciones introducidas por el Protocolo de 1978. Desde esta fecha el Convenio ha sufrido diversas enmiendas para adaptarlo así a las nuevas condiciones técnicas y dar respuesta a los accidentes graves ocurridos estos años (Amoco Cádiz, Herald of Free Enterprise, Exxon Valdez, Estonia, etc).

El Convenio internacional SEVIMAR 1974 entró en vigor el 25 de mayo de 1980 y se publicó en el BOE de | 8.06.1980. El Protocolo de 1978 entró en vigor el I de mayo de 1981 y se publicó en el BOE de 04.05.198I.

Por el Real Decreto 166 ///882, de 25 de junio, "Seguridad de la Vida Humana en la Mar. Aplicación a los barcos nacionales de los preceptos del Convenio Internacional 1974 y su Protocolo de 1978", BOE de 24 de julio, este Convenio es de aplicación a todos los barcos civiles abanderados en España.

Con posterioridad, por Orden de 10 de junio de 1983, "Seguridad de la Vida Humana en la Mar. Normas complementarias para la aplicación del Convenio Internacional 1974 y su Protocolo de 1978 a los barcos y embarcaciones mercantes nacionales", BOE de 
29 y 30 de septiembre, y del I de octubre, se establecen las normas internas que permiten (a veces con una cierta confusión), esta aplicación universal a todos los barcos españoles salvo las embarcaciones de la Armada. La misma Orden encarga a la DGMM el cumplimiento del presente Convenio (...), a quien compete dictar las Ordenes y Resoluciones que se precisen para su aplicación'13.

Finalmente, por Orden del 31 de enero de 1986, BOE del 19 al 26 de febrero de 1986, se hacen una serie de modificaciones de la Orden anterior introduciendo las enmiendas del Convenio aprobadas hasta entonces.

A lo largo de los años, el Convenio Internacional SEVIMAR se ha ido convirtiendo en el palo de pajar imprescindible de la seguridad marítima a nivel internacional. Una vez aprobado el Protocolo de 1978, con su régimen de enmiendas ágil y eficaz, que permite introducir en el Convenio las modificaciones que resulten de las investigaciones sobre los accidentes marítimos importantes, podríamos decir que SEVIMAR constituye una Ley internacional continuamente renovada y puesta al día.

El Convenio original se aplica sólo a los barcos mercantes de más de 500 Toneladas de Registro Bruto (TRB), que hagan viajes internacionales ${ }^{14}$. La Regla I del Capítulo y del Convenio dice:

a) Salvo disposición expresa en otro sentido ${ }^{15}$, las presentes Reglas son aplicables solamente a barcos dedicados a viajes internacionales.

b) En cada Capítulo se definen con mayor precisión las clases de barcos a las que el mismo es aplicable y se indica el alcance de su aplicación.

La Regla 2 de este mismo Capítulo regula las excepciones a la aplicación del Convenio:

a) Todo barco que no esté normalmente dedicado a realizar viajes internacionales pero que en circunstancias excepcionales haya de emprender un viaje internacional aislado, podrá ser eximido por la Administración del cumplimiento de cualquiera de las disposiciones estipuladas en las presentes Reglas, a condición de que cumpla con las prescripciones de seguridad que en opinión de la Administración sean adecuadas para el viaje que haya de emprender.

De "viaje internacional", el mismo Sevimar hace una definición suficientemente clara: un viaje desde un país al que sea aplicable el presente Convenio hasta un puerto situado fuera de dicho país, o viceversa.

El Convenio SEVIMAR no se aplica, salvo disposición expresa en otro sentido, a (Capítulo I, Regla 3):

i) barcos de guerra y barcos para el transporte de tropas;

ii) barcos de carga de menos de 500 toneladas de arqueo bruto;

iii) barcos carentes de propulsión mecánica;

iv) barcos de madera de construcción primitiva; v) yates de recreo no dedicados al tráfico comercial; vi) barcos pesqueros.

De acuerdo con esto, podríamos concluir que a un barco histórico tipo, semejante por ejemplo al barco Santa Eulália ${ }^{16}$, no le afecta el Convenio SEVIMAR: ni por TRB, menor de 500, ni por viajes internacionales, que serán excepcionales según el Plan de usos del barco. Hasta la excepcionalidad de "barcos de madera construcción primitiva" se podría invocar como causa para dejar fuera de la aplicación del Convenio.

Pero no es así:

El Gobierno español ha dispuesto que el presente Convenio [SEVIMAR] sea de aplicación a todos los barcos mercantes nacionales con las exenciones que en cada caso se fijen según las características del tráfico que sirvan o de las misiones que realicen. Se entiende, a tales efectos por barcos mercantes nacionales, los barcos y embarcaciones dedicados al tráfico marítimo, pesca marítima, recreo y servicios de puerto, tanto los que figuran en la Lista Oficial de Barcos como los menores de 20 toneladas, inscritos en las Provincias y Distritos Marítimos ${ }^{17}$.

Esta definición de "barco mercante", distinta y contraria a la que hace la LPEMM, que sólo considera barco mercante al barco civil utilizado "para la navegación con un propósito mercantil, excluidos los dedicados a la pesca" parece incluir en su definición a los barcos históricos. Sin embargo hay dos notas a remarcar. La primera es preguntarse si un barco de época es un barco dedicado al tráfico marítimo, condición indispensable para considerarlo incluido dentro de la definición que hacen las Normas de Aplicación del SEVIMAR. La segunda refuerza la necesidad de diálogo con las autoridades marítimas que tendrán que decidir sobre la seguridad del barco "con las exenciones que en cada caso se fijen según las características del tráfico que sirvan o de las misiones que realicen".

En lo referente a las excepciones fijadas por el Convenio Internacional, que hemos visto antes, las Normas internas de Aplicación cierran la puerta a su utilización ${ }^{18}$ :

No obstante las excepciones anteriores, el Gobierno español exige la aplicación total o parcial de las prescripciones de este Convenio a todos los barcos y embarcaciones nacionales, con excepción de los señalados en el apartado (i) del párrafo a) de la presente Regla, cualquiera que sea su tonelaje y el tráfico que sirvan, y en la extensión que, según su clasificación, se fija en estas normas.

El apartado (i) del párrafo a) de la Regla 3 del SEVIMAR al que hace referencia la disposición "complementaria" anterior, se refiere a "barcos de guerra y barcos para el transporte de tropas", única excepción admitida en España para la aplicación universal de SEVIMAR.

Damos por hecho, a pesar de todo, que este tipo de barcos están afectados por el convenio SEVIMAR. La primera pregunta que tendríamos que responder es 
la clasificación que a efectos de seguridad tendría el barco. Lo que dicen las Normas de Aplicación es que los barcos se clasifican en Barcos de Pasaje, Grupo I, con las siguientes clases:

Clase A.-Barcos con más de 36 pasajeros a bordo. Clase B.-Barcos con no más de 36 pasajeros a bordo. Clase C.-Barcos dedicados al transporte de personal a plataformas marinas, instalaciones fuera de la costa, etc.. Clase G.-Barcos y embarcaciones en viajes menores de 70 millas desde el punto de salida, que no se alejen más de 20 millas de la costa y que naveguen con buen tiempo y períodos restringidos.

Clase H.-Barcos y embarcaciones con un máximo de 250 pasajeros que naveguen con buen tiempo y períodos restringidos, que no se encuentren en ningún momento a más de 15 millas de un puerto de refugio ni a más de 3 millas de la costa.

Clase I.-Barcos y embarcaciones con un máximo de 50 pasajeros, en travesías no mayores de 6 millas y que no se alejen más de 3 millas de la costa (sin restricción en cuanto a época del año).

Clase J.-Barcos y embarcaciones dedicados a navegaciones de aguas abrigadas (bahías, radas, rías, etc).

Clase K-Barcos y embarcaciones dedicados a navegaciones en aguas tranquilas (puertos, canales, ríos, etc).

Grupo II, Barcos de Carga, con las siguientes clases:

Clase Z.-Barcos de carga excepto tanques, de 500 o más toneladas de registro bruto.

Clase Y.-Barcos tanque de 500 o más toneladas de registro bruto.

Clase X.-Barcos de carga de menos de 500 toneladas de registro bruto.

Clase W.-Barcos tanque de menos de 500 toneladas de registro bruto.

Grupo III, Barcos de Pesca, Recreo y Servicios del Puerto, con las siguientes clases:

Clase T.-Remolcadores, lanchas, gabarras, dragas, etc., que salen a la mar.

Clase S.-Remolcadores, lanchas, gabarras, dragas, etc., que no salen a la mar.

Clase R.-Barcos y embarcaciones de pesca.

Clase Q.-Barcos y embarcaciones de recreo no dedicadas al tráfico comercial.

Como vemos, nuestro barco tipo no encaja en ninguno de éstos grupos. En estos casos, las Normas señalan que "los casos que puedan presentarse distintos de los señalados, se clasificarán en los Grupos y Clases que más se le aproximen".

La inclusión en uno u otro Grupo tiene una importancia capital en cuanto a las exigencias de seguridad que se tendrán que observar.

\section{CONCLUSIONES}

I. Nuestras ciudades portuarias, tradicionalmente han vivido de espaldas al frente portuario y todo lo que esto conlleva. Ésta falta de tradición cultural con respecto al mar contrasta con otros países europeos (sobre todo norte-europeos). Este motivo es el principal factor que puede explicar el bajo patrimonio marítimo del que actualmente disponemos.

2. Una potenciación de ésta cultura marítima perdida, pasa por la cohesión y colaboración de diferentes sectores sociales, como la Administración, las Universidades y las diferentes asociaciones tanto públicas como privadas.

3. Dentro del patrimonio marítimo, sin duda es el barco, entendido como un monumento flotante, el que más atención social puede atraer, aunque las dificultades técnicas así como los elevados gastos que genera se oponen inicialmente. La importancia de éste elemento es fácilmente perceptible en el estudio de modelos culturales marítimos foráneos, actualmente en funcionamiento.

4. El pequeño número de embarcaciones históricas, con un plan de usos que contemple la navegación (de hecho su actividad natural), es seguramente el principal argumento que puede explicar el vacío legislativo con el que la actual normativa marítima aplicable se encuentra.

5. Es necesaria una especificación concreta, por lo que se refiere al registro administrativo de las embarcaciones históricas. Ésta demanda no tiene otro objetivo que facilitar administrativamente la aplicación de normas puntuales para este tipo de embarcaciones y que en definitiva sirva para potenciar la creación de un patrimonio marítimo, tanto de carácter público, como privado.

6. La creación de una lista específica para embarcaciones históricas, sin duda representaría la adecuación de las normas a este tipo de embarcaciones. Ésta nueva lista, facilitaría cualquier trámite específico de la embarcación y permitiría la posibilidad de efectuar un censo real sobre estos barcos.

7. Un buen ejemplo para entender el beneficio de la aplicación de una normativa específica, se encuentra en las diferentes Armadas de todo el mundo. Éstas, no sujetas a las reglamentaciones internacionales, por exclusión expresa, disponen de la flexibilidad suficiente como para poder hacer navegar sus embarcaciones, sin encontrar ningún bloqueo administrativo.

8. Por lo que respecta a la dotación, así como por su preparación, también nos encontramos con que, una normativa diseñada expresamente redundaría en la seguridad del barco. No se contempla la formación práctica (a través de cursos, como los que actualmente se aplican a barcos también "especiales": petroleros, quimiqueros o hasta barcos de recreo), de una dotación necesariamente cualificada. Las exigencias de la Administración son realmente mínimas y no podemos dejar de señalar que preparación es sinónimo de seguridad. 
9. La seguridad de los barcos no puede dejarse en manos de exenciones administrativas. Éstas son actualmente la única salida posible, pero no garantizan un modelo de seguridad apropiado.

10. Las normativas internacionales referentes a la seguridad de los barcos necesitan de una adecuación para los barcos históricos (el hecho de no encontrar un grupo de clasificación ajustado, ya es una buena prueba). Sin embargo, sin perder de vista que alejarse de los estándares vigentes no tiene que significar nunca, la disminución en la seguridad. Simplemente es una adaptación coherente. o de Comercio, Libro III, "Del Comercio Marítimo", artículos 573 a 869), está falto de una definición precisa de "buque", quizás porqué es un texto fechado el 22 de agosto de 1885 que ha permanecido sorprendentemente intacto desde esta remota fecha.

2. Las Capitanías Marítimas están reguladas por el Real Decreto 1246/1995, de 14 de Julio, BOE de 01.08.1995.

3. El Registro Mercantil está reglamentado por el Real Decreto 1784/1996, de 19 de julio, aunque en todo aquello que hace referencia a la inscripción de buques en este registro sigue vigente el Título $\vee$ del Reglamento aprobado el I 4 de diciembre de 1956, BOE del 7 de marzo de 1957.

4. BOE del 27 de diciembre de 1971. Ver también el artículo 91 del Convenio de las Naciones Unidas relativo al Derecho del Mar, firmado en Montego Bay el 10 de diciembre de 1982, ratificado por España por Instrumento de 20 de diciembre de 1996 (BOE de 13 de febrero de 1997).

5. José Luis Gabaldón García y José María Ruiz Soroa, Manual de Derecho de la Navegación Marítima, Marcial Pons Ediciones Jurídicas y Sociales, Madrid 1999, página I8I.

6. La LPEMM creó también el "Registro Especial de Barcos y Empresas Navieras", localizado en Canarias, con el propósito de abaratar las condiciones de explotación de los buques inscritos en el Registro ordinario.

7. Real Decreto 1027/1989, de 28-7-1989. Publicado en BOE de |5-8-1989, correcciones al BOE |-2-1990.

8. El Convenio Internacional sobre Normes de Formación, Titulación y Guardias para la Gente de Mar fue aprobado por la OMI, en Londres, el 07.07.1978 y entró en vigor el 28.04.1984.Se publicó en el BOE de 07.I I.1984. En 1995 se aprobaron unas enmiendas de gran calado al Convenio (enmiendas que entraron en vigor el 01.02.1997, BOE de 20.05. 1997), cosa por la cual el Convenio es referido como STCW/95.

9. BOE de 16.07.1964.

10. Texto Refundido del Estatuto de los Trabajadores, Real Decreto Legislativo I//995.

|l. RD |56|//995.

12. BOE de 15 y 16 de marzo de $197 \mid$

13. Agregado doméstico de la Regla 2, Capítulo I de SEVIMAR. Orden de 10.06.1983

14. En el arqueo de un barco, su TRB, constituye una medida administrativa con efectos fundamentalmente fiscales y recaudatorios, y su relación con las medidas reales del barco (su eslora, desplazamientos, etc.) discurre por tortuosidades a veces difíciles de comprender. El arqueo de un barco pretende medir su capacidad comercial y se calcula de acuerdo con unas reglas comprendidas en el Convenio Internacional sobre Arqueo de Buques, hecho en Londres el 23 de junio de 1969 (BOE de 15.09.1969). Este Convenio, que entró en vigor el I 8 de julio de 1982, cambió las reglas de arqueo y las denominaciones de Tonelaje de Registro Bruto (TRB) y Tonelaje de Registro Neto (TRN), por las nuevas de GT y NT respectivamente.

15. La única disposición en otro sentido, aplicando el Convenio a los barcos menores de 500 TRB, es el Capítulo V dedicado a la seguridad de la navegación.

16. El Pailebote Santa Eulália, es propiedad del Museo Marítimo de Barcelona, y actualmente puede visitarse en el "moll de la fusta" del puerto de Barcelona.

17. Agregado doméstico a la Regla I del Capítulo I de SEVIMAR. Orden de 10.06.1983.

18. Agregado doméstico a la Regla 3 del Capítulo I del SEVIMAR. Orden de 10.06.1983. 